\title{
Exer-Learning Games: Transferring Hopscotch from the Schoolyard to the Classroom
}

\author{
Martina Lucht, Steffi Domagk, and Martin Mohring \\ Fraunhofer Institute for Digital Media Technology IDMT, \\ Hirschlachufer 7, 99084 Erfurt, Germany \\ Martina.Lucht@idmt.fraunhofer.de
}

\begin{abstract}
In this paper we present the idea of Exer-learning games integrating the element of exercise into serious games. The combination of motion, learning and playing is assumed to facilitate intrinsic motivation and learning achievements. For the application of exer-learning games, the concept of HOPSCOTCH is introduced that is inspired by the popular childrens game. Two demonstrators of this concept have been realized and evaluated: HOPSCOTCH pad and HOPSCOTCH mobile. First results show a positive feedback from scholars and teachers. Finally, future directions for our research on HOPSCOTCH are described that could model research on exer-learning games as well as their application in the classroom.
\end{abstract}

Keywords: digital game-based learning, serious games, exercise, learning, playing, exer-learning games, HOPSCOTCH, mobile learning.

\section{Introduction}

Learning and playing have long been tried to connect in order to use the intrinsic motivation of playing for persistent and joyful knowledge acquisition. In this paper we discuss the aspect of learning while playing, including a positive effect of integrating exercise in the learning process, as part of the play action. We therefore introduce a new genre of digital learning games that combine exercise, learning and playing: exer-learning games. The assumed positive effects of exerlearning games refer to the endurance of the willingness to learn and the quality of knowledge acquisition, especially the accessibility of knowledge. The popular children's game "Hopscotch" has been adapted to train English vocabulary while jumping on a sensor pad. This new concept for excer-learning games has been developed at the Fraunhofer Institute of Digital Media Technology (IDMT) and aims at the joyful and physically active acquisition of factual knowledge. First evaluations of two developed demonstrators "HOPSCOTCHpad" and "HOPSCOTCH mobile" are presented in this paper along with subsequent future directions for research and the integration of Excer-learning games in school lessons. We argue that Excer-learning games may facilitate knowledge acquisition and intrinsic motivation to learn as well as provide new approaches for teaching and practicing in classrooms. 


\section{Exercise Learning vs. Conventional Learning}

Children's play and learning are interconnected. "Children explore and acculturate the world through play, extend their skills and competencies, and experiment with possible selves. Only at a later point during elementary school do entertainment and learning start to drift apart. Older children may even associate play with being noneducational and learning with being anything but enjoyable" [23]. Formal learning seems mostly to be associated with sitting at a desk. This applies to school, in which the children spend most of the time sitting still, and to homework that is also mostly done in a sitting posture. Assuming a natural urge to move, especially among children of primary school age, it is liable that the necessary suppression of movement during learning can lead to a negative connotation.

\section{$2.1 \quad$ Exercise}

Unlike earlier, when students have physically worked after school or played outside, in the media age also recreation has become rather motionless. The German children and adolescents survey (KiGGS) notes that the "[...] chance on physical and sporting inactivity in the age between 11 to 17 years increases with each passing year by about $30 \%$ on average" [16. Studies show that young people spend more and more free time with media reception instead of playing outside (e.g. 3130]). This trend has enormous implications for the mental, physical and social development of children and adolescents, because exercise affects not only physical health. "In addition to positive effects on the organic and motoric development the importance of the psychosocial well-being, personal development and learning of social skills is to emphasize" [16. Therefore the lack of exercise is not only problematic for the physical health of young people, it also affects psychological and social aspects.

\subsection{Exergames}

In the End of 2006 Nintendo presented the Wii in Europe and increased the popularity of Exergames. The so called Exercise Games (Exergames) are games where the input is done with body movements rather then with the finger. The body movements are targeted with special input devices that work with accelerometers. The players do not sit in front of a Computer but "bowl", "box" or "hit" with the input device. These body movements are detected sensor based and are integrated in the game on the monitor. Sensor pads were used for dance games, where the player must step on a field with an arrow. The goal of the dance game is to hit the correct arrow direction at the correct point of time, given on the monitor. Most popular are "Dance Dance Revolution", "In The Groove" and "StepMania". In the field of games research, Exergames were studied mainly in terms of their health effects 3419. The health aspect of exergames is obvious, but could the combination of games, movement and learning content in digital games offer a new dimension of knowledge acquisition? 


\subsection{Digital Game-Based Learning}

The concepts "serious games", "game-based learning" and "digital educational games" - that are used widely synonymous - mark the initiative to use the potential of digital games to actively engage players for learning (e.g. [28|23|21]). They aim at the combination of joyful playing and learning that is defined as intentional acquisition of knowledge through practice and training. The primary goal of game-based learning however, is not the fun-aspect but the benefits for learning namely an increase of intrinisic motivation and knowledge acquisition [93. Intrinsic motivation arises from activity-specific incentives that are inherent in games but not necessary in learning activities 35. Learning activities are often performed to reach certain consequences (good marks, exams, etc.) and therefore have to be conceptualized as extrinsically motivated 22. Game-based learning tries to create intrinsic motivation for learning through connected game activities that offer activity-specific incentives.

Recent game-based learning initiatives focus on deeper learning rather than the acquisition of factual knowledge and on broader educational issues outside the classroom [8/7/15]17/23]. "The current focus on the research and development of video games and simulations for learning is not translating into widespread practice in classrooms" 26. However, first attempts have been made to integrate digital game-based learning into school lessons [27]11.

The combination of learning and gaming is a promising attempt to create new enjoyable ways of knowledge acquisition. The aspect of exercise however, has not yet been integrated into this discussion. We therefore propose a new genre of learning games: Excer-learning games.

\subsection{Exer-Learning Games}

The educational aspect of Exergames with regard to the acquisition of knowledge seems to be a desideratum. The advantage of a combination between learning and movement, however, can be concluded from different interdisciplinary scientific discoveries. Theories of exercise- and sports education for example, describe that development and differentiation are connected with psychomotor behaviour patterns, cognitive and personal-psychological elements 381. Thus, exercise learning can be seen in context of a structuring process of the brain and also a process in which the learner's self-confidence can be strengthened [36. In addition, medical studies show that exercise leads to an increase in concentration [24.

Studies in pedagogics and psychology have shown that even minimal physical activities can support the learning process because actively performed tasks are memorized better than passively received information (e.g. [5]4|10]37. In the current scientific discussion these outcomes are picked up. Tabbers 33] showed that an animation is better memorized when the learner can reproduce the movements of the animation on the screen with the mouse instead of just watching passively. These outcomes correspond with new findings in the neurosciences. These show that the human language- and exercise system in the brain are closely related. Physical activities may lead to additional links that support an 
easier recall of the information learned (e.g. [12 28]). Critically it is to consider that the extensive involvement of various movements during the learning process, could increase cognitive load, thus exceed working memory capacity and even hinder learning. With increasing practice however, the task performance (performing the required movements) should become automated - not needing additional working memory resources 25]. Furthermore, cognitive load theory [32] considers learning in terms of efficiency rather than effectiveness: learning faster, without mental stress [13], whereas Excer-learning games consider learning in terms of effectiveness: investing more learning time due to a higher intrinsic motivation (having fun while learning) and challenge as one important incentive of game play.

We assume that Excer-learning games lead to better knowledge acquisition than traditional learning strategies. This assumption is justified by different theoretical approaches. The link between exercise and learning can fulfil a mnemonic function by the movement (e.g. dance steps) as a kind of crib [29]. In addition Piaget [20] states that the evolution of morphogenetic regulation is an important component of psychomotor and cognitive development.

\section{HOPSCOTCH - A Concept for Excer-Learning Games}

Hopscotch is a children's game where numbered squares are to be hopped in the sequence of their numbers. The course is drawn with chalk on pavement. It is one of the world's most popular outdoor games for children, often played in the schoolyard. The children's game "Hopscotch" inspired the idea of HOPSCOTCH, presented in this chapter. The concept of HOPSCOTCH was developed at the Fraunhofer Institute for Digital Media Technology (IDMT), Germany. On the basis of software, scholars are motivated to solve various tasks by jumping on fields. The fields are reminiscent of the keyboard of a mobile phone, they are multidimensional: Tipping on a field once, twice or three times gives a different letter (e.g. A, B, C), comparable to writing an SMS. The tasks are shown on a monitor. The playing component of HOPSCOTCH is to move the body as quick as possible on the field, touching the correct fields in a given order as fast as possible. The learning component is the event that starts the game: What fields are to be touched in what order.

In serious games the learning aspects are often less enjoyable add-ons to the game [23]. In HOPSCOTCH the learning aspect is fully integrated into the game, since it is the event that starts the actual game process.

\subsection{Two Applications of the HOPSCOTCH Concept}

On the basis of the described concept, two applications were realized: HOPSCOTCHpad and HOPSCOTCHmobile.

Realisation on a Sensor Pad (HOPSCOTCHpad). For scientific research on Exer-learning games a first demonstrator of HOPSCOTCH was developed, 


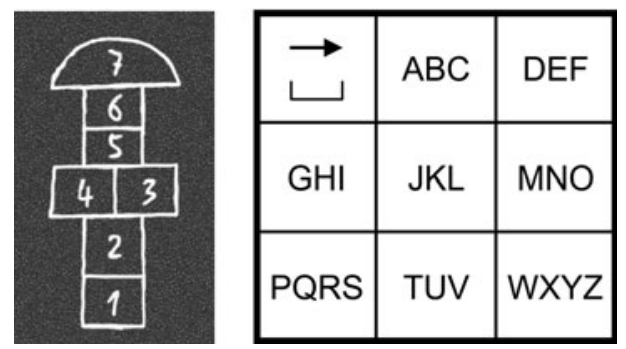

Fig. 1. Playing field of the childrens game "Hopscotch" (left), input device for HOPSOCTCH (right)

using a dance pad with nine sensor fields as an input device. As learning content an English vocabulary trainer was programmed on basis of "Unity" game engine. Via monitor the player is asked to translate a German word into English and enter the solution on the dance mat. The integrated high score takes the time that was used to "write" the correct answer. Incorrect letters are ignored, only when the correct letter was entered, the next can be jumped. The correct input is commented by a positive feedback with a short animation as it is usual in computer games (immediate feedback). HOPSCOTCHpad can be played in single- and multipayer modus.

Realisation on a Mobile Phone (HOPSCOTCHmobile). Studies confirm that mobile devices are very attractive to young people 3031. 95\% of young people own a mobile phone and use it mostly for SMS and for playing. Additionally, the rapidly progressing technical development, also in the area of the mobile devices, opens a huge number of new possibilities for mobile learning, gaming and entertainment.

Because of this IDMT ported the gaming concept of HOPSCOTCH to mobile devices. After creating different interaction concepts one was implemented and evaluated. The focus lay on the fact that a mobile version of the game should run on many devices. During the implementation the concept was created on HTC Touch Diamond2 programmed on "C-Sharp". This Version was ported on Sony Ericsson W995i based on "Java ME".

The aspect of exercise was realized by using an accelerometer (g-sensor). This technology allows recognizing the exercises (in this case the jumps) of the player. The rotation around the axes (the pitch) of the mobile phone is used to determine the jumping-direction. For example: if the player rotates the mobile device to the back and jumps up, the players' character moves one step back. Similar to the sensor pad version, wrong letters are ignored while only right letters are entered.

Because of the small display of mobile phones additional feedback is very important. Different sounds for any field and the use of vibration generates haptical and acoustical feedback. Correct spellings are rewarded with short animations. 


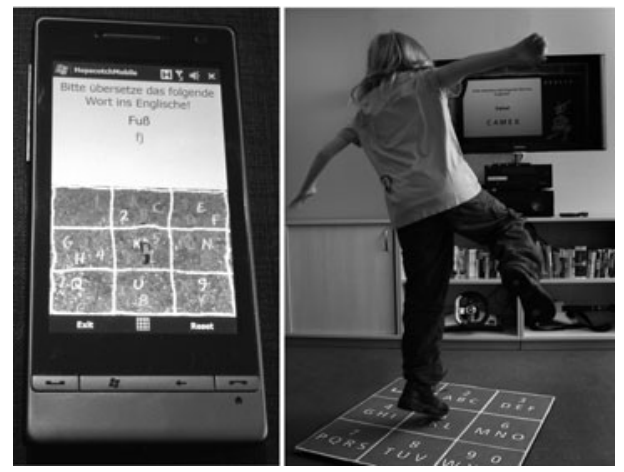

Fig. 2. HOPSCOTCHpad (left) and HOPSCOTCHmobile (right)

\subsection{Evaluation of the HOPSCOTCH Applications}

The two prototypes first were evaluated in terms of acceptance and fun. This was to investigate whether the theoretical assumed positive effects were actually met by the integration of exercise into the learning process.

The sensor pad version of HOPSCOTCH was evaluated on a children's trade show in Erfurt, a survey of scholars $(\mathrm{N}=57)$ aged between eight and twenty years $(\mathrm{M}=11.5, \mathrm{SD}=1.8)$. The sample consisted of young visitors to the fair, who self-chosen played HOPSCOTCHpad and school classes who were invited to hold English lessons with HOPSCOTCHpad. Children and adolescents who played at least 10 minutes were invited to answer a questionnaire, the exact play time was not measured. $78.9 \%(\mathrm{n}=45)$ of the respondents were female and $21.1 \%$ male $(\mathrm{n}=12)$. Additionally the accompanying teachers were asked to fill out an extra questionnaire $(\mathrm{n}=11)$.

The mobile version of HOPSCOTCH was evaluated in a child and youth centre in Gotha, evaluating twenty three children aged between eight and twenty one years $(\mathrm{M}=13.13, \mathrm{SD}=3.84, \mathrm{~N}=23) .43 .5 \%(\mathrm{n}=10)$ of the probands were female and $56.5 \%(\mathrm{n}=13)$ were male. After a short instruction how to play, the children played at least five minutes followed by a questionnaire.

The Opinion of the Pupils. On a scale from 1 ("very good") to 5 ("poor") the probands were asked to rate their first impression of the game. 96.5\% stated as their first impression as "good" $(21.1 \%)$ or "very good" (75.4\%) for HOPSCOTCHpad. When the scholars had to decide whether it is more of a sports or an educational game, the vast majority $(77.2 \%)$ associated HOPSCOTCH pad as a learning game. However the element of exercise seems to be important: $48.2 \%$ of the players want to exercise with HOPSCOTCHpad. $62.5 \%$ of the respondents would use it for learning. The majority prefers to play together with friends $(80.4 \%)$ instead of playing alone $(1.8 \%)$. In general there was a very positive feedback to HOPSCOTCHpad; children came again and again to play. The fact that $56.1 \%$ of the interviewed would renounce on another present for getting HOPSCOTCHpad underlines this impression. 
The first impression of HOPSCOTCHmobile was "very good" (65.2\%) or "good" (34.8\%) on a scale from 1 ("very good") to 5 ("poor"). A second indicator for the attractivity of HOPSCOTCHmobile gives the factor "play fun" that was also rated as very good to well $(\mathrm{M}=1.41$; $\mathrm{SD}=0.60)$ on scale from 1 ("very good") to 5 ("poor"). The questionnaire also measured the attractiveness of the new game control. Although the combination of pitching and jumping seems to be a little bit tricky (because the players have to direct the phone in a correct position while jumping) the probands rated the game control as very good (M $=1.41 ; \mathrm{SD}=0.47)$.

The Opinion of the Teachers. The teachers $(\mathrm{n}=11)$ also rated HOPSCOTCHpad very positive. Their first impression of HOPSCOTCHpad was for $72.7 \%$ "very good" and for $27.3 \%$ "good", rated again on a scale form 1 ("very good") to 5 ("poor"). From their point of view, the game has "high" $(81.8 \%)$ or "very high" (18.2\%) potential for learning. Only $18.2 \%$ see the potential at an average, none of them see a low potential. The teachers could very well imagine using HOPSCOTCH for their classes: $72.7 \%$ see a "very high" or "high" potential for HOPSCOTCH as a teaching aid.

The mobile version of HOPSCOTCH was not yet presented to the teachers.

\subsection{Interim Conclusion}

The pedagogic concept of HOPSCOTCH was applied in two demonstrators: HOPSCOTCHpad and HOPSCOTCHmobile. Both got positive feedback from children. They love playing HOPCOTCH even though they classify it as a learning game. The teachers also see high potential in this concept and could very well imagine using it as teaching aid in school.

\section{Next Steps}

Initial tests show positive feedback from students and teachers for HOPSCOTCH as a learning concept. The research interest now comprises two aspects (1) conducting empirical studies on the effectiveness of Excer-learning games based on the HOPSCOTCH concept and (2) bringing HOPSCOTCH into the classroom as a teaching aid.

\subsection{Specifications for HOPSCOTCH as a Teaching Aid}

To what extent is it possible to integrate HOPSCOTCH into school lessons and how could this happen? To answer this question a qualitative survey with teachers will be realized. It aims at specifications for a school version of HOPSCOTCH. As Simpson and Stansberry [26] state, it is important for the teachers to anchor innovations to what they are familiar with. Therefore initial semi-structured interviews will be organised, in which the conditions of school life, the learning standards, the lesson planning, etc. will be assessed, to find the possibilities of using HOPSCOTCH in classes and the opportunities and risks that occur. 
While this first survey with interviews is focusing on the conscious schemes and opinions of the teachers, a second survey will also evaluate the unconscious opinions. By using the repertory grid method [14618 the unknowingly constructs of HOPSCOTCH in school lessons will be made available. The major goal of this second survey is to evaluate the inner acceptance of the teachers to a refinement of their classes in general and to a refinement in terms of exercise in special.

\subsection{Empirical Studies on the Effectiveness of Exer-Learning Games Based on HOPSCOTCH}

Do children actually gain more factual knowledge when playing HOPSCOTCH than with traditional learning strategies? The assumed positive effect of Excerlearning games on intrinsic motivation and learning will be investigated in experimental studies. Therefore an Excer-learning game for English vocabulary will be implemented on HOPSCOTCHpad and compared to traditional learning strategies for the same set of English vocabularies.

\subsection{Conclusions}

In this paper we introduced the idea of Excer-learning games. As outlined it seems to be promising to integrate basic elements of serious games like competition and highscores and combine them with the element of exercise that goes beyond input devices like mouse or keyboard. Two applications of the HOPSCOTCH concept were realized, one with a sensor pad technology and one on a mobile phone. First results with these demonstrators show positive feedback from children and teachers. Exercise could be a catalyst that integrates the intrinsic motivation of playing into the learning process in a better way then traditional serious games. Further projects focus on the integration of this concept into school lessons. In sum, HOPSCOTCH could well be a new inspiration to the learning process at home and in school classes.

\section{Acknowledgements}

The present research has been partially funded by the Federal Ministry of Education and Research within the project "MEMORI" under contract 01GI0902 and the Thuringian Ministry of Education, Sciences and Culture within the project "iCycle" under contract PE 004-2-1.

\section{References}

1. Bietz, J., Laging, R., Roscher, M.: Bildungstheoretische Grundlagen der Bewegungs- und Sportpädagogik. Schneider Verlag, Baltmannsweiler (2005)

2. Brannigan, C., Owen, A.: Game based learning or learning based games? a case study. In: Burmester, M. (ed.) Digital Game Based Learning - Proceedings of the 4th International Symposium for Information Design 2nd of June 2005 at Stuttgart Media University, pp. 179-196. Universitaetsverlag, Karlsruhe (2006) 
3. Dumbleton, T., Kirriemuir, J.: Understanding digital games. Sage Publ., London (2006)

4. Engelkamp, J.: Memory for actions. Psychology Press/Taylor \& Francis, England (1998)

5. Engelkamp, J., Zimmer, H.D.: Human memory. Hogrefe \& Huber, Seattle (1994)

6. Fromm, M.: Repertory Grid Methodik. Deutscher Studien-Verl., Weinheim (1995)

7. Gee, J.P.: Good video games and good learning: Collected essays on video games, learning, and literacy. No. v. 27 in New literacies and digital epistemologies, Lang, New York [u.a.] (2007)

8. Gee, J.P.: What video games have to teach us about learning and literacy. Palgrave Macmillan, Basingstoke (2007), Rev. and updated ed. edn.

9. Goldstein, J.H., Buckingham, D., Brougre, G.: Introduction: Toys, games, and media. In: Goldstein, J.H., Buckingham, D., Brougre, G. (eds.) Toys, games, and media, pp. 1-10. Erlbaum, Mahwah (2004)

10. Grabowski: Generative learning: Past, present, and future. In: Handbook of Research on Educational Communications and Technology, pp. 897-918. Macmillian, New York (2004)

11. Hawlitschek, A.: Spielend lernen aber wie? zum didaktischen design von serious games fü die schule. In: Schwill, A., Apostolopoulos, N. (eds.) Lernen im digitalen Zeitalter

12. Hurley, S.: The shared circuits model ( $\mathrm{scm}$ ): how control, mirroring, and simulation can enable imitation, deliberation, and mindreading. Behav. Brain Sci. 31(1), 1-22 (2008), discussion 22-58 (February 2008), http://dx.doi.org/10.1017/S0140525X07003123

13. Kalyuga, M.: Enhancing instructional efficiency of interactive e-learning environments: A cognitive load perspective. Educational Psychology Review 19, 387-399 (2007)

14. Kelly, G.A.: The psychology of personal constructs. Norton, New York (1955)

15. Kline, S.: Learners, spectators, or gamers? an investigation of the impact of digital media in the media-saturated household. In: Goldstein, J.H., Buckingham, D., Brougre, G. (eds.) Toys, Games, and Media, pp. 131-156. Erlbaum, Mahwah (2004)

16. Lampert, T., Mensink, G.B., Romahn, N., Woll, A.: Physical activity among children and adolescents in germany. results of the german health interview and examination survey for children and adolescents (kiggs). Bundesgesundheitsblatt Gesundheitsforschung Gesundheitsschutz 50(5-6), 634-642 (2007)

17. Linderoth, J., Lindström, B., Alexandersson, M.: Learning with computer games. In: Goldstein, J.H., Buckingham, D., Brougre, G. (eds.) Toys, Games, and Media, pp. 157-176. Erlbaum, Mahwah (2004)

18. Lucht, M.: Erfüllung der Informations- und Meinungsbildungsfunktion im Fernsehen: Eine experimentelle Studie zum Vergleich von herkömmlicher Dokumentation und Multiperspektivendokumentation. Müller, Saarbrücken (2007)

19. Newsvote: Computer games 'burn up calories' (2007), http://newsvote.bbc.co.uk/2/hi/health/6376637.stm

20. Piaget, J.: Nachahmung, Spiel und Traum, 1st aufl edn., Klett, Stuttgart (1975)

21. Prensky, M.: Digital Game-Based Learning. Paragon House Publishers (2007)

22. Rheinberg, F., Vollmeyer, R., Burns, B.D.: Motivation and self-regulated learning. In: Motivational Psychology of Human Developement, pp. 81-108. Elsevier, Amsterdam (2000)

23. Ritterfeld, U.: Introduction. In: Serious games: Mechanisms and Effects, pp. 3-9. Routledge, New York (2009) 
24. Ritteser, M.J.: Bewegung und Lernen - Auswirkungen von Bewegung in der Schule auf Konzentration, Merkfähigkeit und Befindlichkeit, Grin, München (2007)

25. Schnotz, W., Kuerschner, C.: A reconsideration of cognitive load theory. Educational Psychology Review 19(4), 469-508 (2007), http://springerlink.com/content/nt077668737230p6/

26. Simpson, E., Stansberry, S.: Video games and teacher development: Bridging the gap in the classroom. In: Games: Purpose and Potential in Education, pp. 1-22. Springer, US (2009), http://www.springerlink.com/content/p4448631p1800276/

27. Squire, K.D.: Replaying history: learning world history through playing "civilization iii". Ph.D. thesis, Indianapolis, IN, USA, chair-Barab, Sasha A (2004)

28. Stevanoni, E., Salmon, K.: Giving memory a hand: Instructing children to gesture enhances their event recall. Journal of Nonverbal Behavior 29(4), 217-233 (2005), http://springerlink.com/content/pn3g00501v1j8087/

29. Stork, A.: Vokabellernen. Giessener Beiträge zur Fremdsprachendidaktik, Narr, Tübingen (2003)

30. Südwest, M.F.: Jim-studie 2008: Jugend, information (multi-) media. basisuntersuchung zum medienumgang 12- bis 19-jähriger (2008), http://www.mpfs.de/fileadmin/JIM-pdf08/JIM-Studie_2008.pdf

31. Südwest, M.F.: Kim-studie 2008: Kinder und medien, computer und internet: Basisuntersuchung zum medienumgang 6- bis 13-jähriger in deutschland (2008), http://www.mpfs.de/fileadmin/KIM-pdf08/KIM2008.pdf

32. Sweller, J., Chandler, P.: Evidence for Cognitive Load Theory. In: Cognition and Instruction, vol. 8, pp. 351-362. Taylor and Francis, London (1991)

33. Tabbers, H.: Enhancing learning from dynamic visualizations: An embodied perspective. Paper Presented at the Biennial Conference of the European Association for Research on Learning and Instruction (EARLI), Amsterdam, Netherlands, August 25-29 (2009)

34. Unnithan, V.B., Houser, W., Fernhall, B.: Evaluation of the energy cost of playing a dance simulation video game in overweight and non-overweight children and adolescents. Int. J. Sports Med. 27(10), 804-809 (2006), http://dx.doi.org/10.1055/s-2005-872964

35. Vorderer, P.: Motivation. In: Psychology of Entertainment, pp. 3-18. Erlbaum Assoc., Mahwah (2006)

36. Werning, B.R., Palmowski, W., Sassenroth, M.: Der Bereich der Wahrnehmung und Bewegung als sonderpädagogischer Förderbedarf. In: Sonderpädagogik. Lernen, Verhalten, Sprache, Bewegung und Wahrnehmung, pp. 284-318. Oldenbourg, München (2002)

37. Wittrock, M.C.: Generative learning processes of the brain. Educational Psychologist 27(4), 531-541 (1992)

38. Zimmer, R. (ed.): Wahrnehmen, bewegen, lernen - Kindheit in Bewegung. Hofmann, Schorndorf (2004) 